\title{
La hidroxicloroquina no reduciría la portación viral del nuevo coronavirus (COVID-19)
}

\author{
Hydroxychloroquine would not reduce viral carrying of the new coronavirus (COVID-19)
}

Chen J et al. J Zhejiang Univ (Med Sci), 2020, 49(1):0-0.

\section{Comentado de:}

Chen J et al. J Zhejiang Univ (Med Sci), 2020, 49(1): 0-0. ${ }^{1}$

\section{Objetivo}

Determinar la eficacia de la hidroxicloroquina en el tratamiento de pacientes con COVID-19.

\section{Diseño, lugar y participantes}

Ensayo clínico controlado aleatorizado de 30 pacientes adultos con diagnóstico de COVID-19, reclutados del 6 al 25 de febrero de 2020 en Shanghai, China.

\section{Intervención}

Sulfato de hidroxicloroquina $400 \mathrm{mg}$ diarios durante 5 días. El grupo control recibió cuidados estándar. Ambos grupos reci- bieron nebulizaciones con interferón, algunos lopinavir/ritonavir otros recibieron umifenovir y antibióticos según criterio médico.

\section{Medición de resultados principales}

Se evaluó la presencia del virus con reacción en cadena de polimerasa (PCR) de secreciones respiratorias con muestreos consecutivos hasta lograr un resultado negativo. También se reportaron la mortalidad, los eventos adversos y los cambios en la tomografía de pulmón.

\section{Resultados principales}

Se resumen los resultados en la Tabla 1.

Tabla 1. Desenlaces principales del estudio. Nota: PCR: reacción en cadena de polimerasa. TC: tomografía computada

\begin{tabular}{|l|c|c|c|}
\hline \multicolumn{1}{|c|}{ Desenlace } & Hidroxicloroquina $(\mathrm{n} / \mathrm{N})$ & Cuidado estándar (n/N) & $\mathrm{p}$-valor \\
\hline PCR negativa a los 7 días & $13 / 15$ & $14 / 15$ & 0,54 \\
\hline Mortalidad & 0 & 0 & $\mathrm{~N} / \mathrm{A}$ \\
\hline $\begin{array}{l}\text { Empeoramiento en la TC de pul- } \\
\text { món }\end{array}$ & $5 / 15$ & $7 / 15$ & 0,45 \\
\hline Eventos adversos & $4 / 15$ & $3 / 15$ & 0,66 \\
\hline
\end{tabular}

\section{Conclusiones}

El pronóstico de los pacientes comunes con COVID-19 es bueno y se necesitan estudios de mayor tamaño de muestra para investigar los efectos de la hidroxicloroquina en el tratamiento de esta enfermedad. Investigaciones posteriores deberían determinar un mejor criterio de valoración y considerar plenamente la viabilidad de los estudios experimentales, como así también el tamaño adecuado de la muestra.
Fuente de financiamiento/Conflicto de interés de los autores: Este estudio fue financiado por: Shanghai Science and Technology Commission (20431900103); Fudan University First-Class University and FirstClass Discipline Construction Project (IDF162005); Zhejiang University New Coronary Virus Pneumonia Emergency Research Special Project (2020XGZX030); Special Project in the Research Center for New Coronavirus "2019-nCoV. of Shanghai Public Health Clinical Center (2020YJKY01) Shanghai Key Specialty Infectious Disease Project (shslczdzk01102); Shanghai "Yinyuanxingxing"Medical Talent Project (2019-72). Los autores no declararon conflictos de interés.

\section{Comentario}

La pandemia de COVID-19, causada por el nuevo coronavirus (SARS-CoV-2) está causando una conmoción internacional por los retos que implica su amplia diseminación, las controversias alrededor de cuál es la mejor estrategia para su contención y la ausencia de tratamientos específicos que hayan sido probado ser efectivos.

A raíz de un estudio francés ${ }^{2}$ de diseño observacional, con 36 pacientes tratados con hidroxicloroquina y, en algunos casos, azitromicina, se han generado hipótesis acerca de las propiedades de este fármaco ampliamente conocido, primero como antimalárico y segundo, como antiinflamatorio para enfermedades autoinmunes como la artritis reumatoidea y el lupus eritematoso sistémico. Sin embargo, el estudio mencionado tiene fallas metodológicas críticas como: a) la falta de aleatorización, b) el disbalance en las co-intervenciones, c) irregularidades en la medición del desenlace, d) la falta de reporte de desenlaces clínicos (sólo reporta los valores de PCR y no sabemos el pronóstico de los pacientes tratados). 
A pesar de esta penosa fuente de evidencia, el actual presidente de los EE.UU., Donald Trump, afirmó en Twitter que este medicamento podría ser uno de los "más grandes game changers de la historia de la medicina" 3 . Días después, múltiples organismos internacionales, incluido el Ministerio de la Salud de la Argentina, recomendaron el uso sistemático de esta droga en pacientes con neumonía por COVID-19 grave o con factores de riesgo para enfermedad severa ${ }^{4}$. Si bien la hidroxicloroquina es un fármaco seguro en un uso a corto plazo y tiene bajo costo, agregarlo a un esquema terapéutico en pacientes con múltiples comorbilidades sin un beneficio clínico probado sólo agrega riesgos de reacciones adversas e interacciones farmacológicas. De hecho, días después un hombre falleció en Arizona, EE.UU., por intoxicarse con una provisión local de cloroquina que tenía en un producto para limpieza de acuarios ${ }^{5}$. Aún más, el acopio masivo de hidroxicloroquina podría generar faltantes en personas en tratamiento crónico de enfermedades reumáticas, para las cuales se ha probado su efectividad.

Este nuevo ensayo ${ }^{1}$ sigue aportando evidencia de baja calidad (debido a que hubo co-intervenciones desbalanceadas y su tamaño muestral era muy pequeño), pero tiene hallazgos que contradicen al estudio francés, de mucha peor calidad metodológica. ¿Qué habría sucedido si el ensayo clínico se hubiese publicado antes? ¿Seguiría siendo un fármaco cuyo uso rutinario estaría recomendado?

\section{Conclusiones del comentador}

Necesitamos ejercer una extrema cautela en la valoración de terapias emergentes en general, y en particular en el caso de COVID-19, debido a la gran sensibilidad y esperanza del público para encontrar medidas paliativas para esta pandemia que está azotando al mundo y, pronto, a nuestro país. Los líderes de opinión, incluyendo los medios de comunicación, los profesionales de la salud y los tomadores de decisión a nivel gubernamental, deben ejercer la cautela al implementar sistemáticamente fármacos de dudosa eficacia fuera del contexto de la investigación.

Juan Víctor Ariel Franco [ Servicio de Medicina Familiar y Comunitaria, Hospital Italiano de Buenos Aires; Departamento de Investigación, Instituto Universitario Hospital Italiano. juan.franco@hospitalitaliano.org.ar ]

Franco JVA La hidroxicloroquina no reduciría la portación viral del nuevo coronavirus (COVID-19). Evid Actual Pract Ambul. 2020;23(1):e002051. Comentado de: Chen J, Liu D, Liu L, et al. A pilot study of hydroxychloroquine in treatment of patients with common coronavirus disease-19 (COVID-19). J Zhejiang Univ (Med Sci), 2020, 49(1): 0-0

\section{Referencias}

1. Chen J, Liu D, Liu L, et al. A pilot study of hydroxychloroquine in treatment of patients with common coronavirus disease-19 (COVID-19). Journal of Zhejiang University (Medical Science). 2020;49(1):0-0. Available from: 10.3785/j.issn.1008-9292.2020.03.03.

2. Gautret P, Lagier JC, Parola P, et al. Hydroxychloroquine and azithromycin as a treatment of COVID-19: results of an open-label non-randomized clinical trial. International Journal of Antimicrobial Agents. 2020;p. 105949. Available from: 10.1016/j.ijantimicag.2020.105949.

3. Trump D. HYDROXYCHLOROQUINE and AZITHROMYCIN, taken together, have a real chance to be one of the biggest game changers in the history of medicine. The FDA has moved mountains - Thank You! Hopefully they will BOTH (H works better[...]); 21 de marzo de 2020 . Available from: https://twitter.com/DrDenaGrayson/status/1241451795848859648?ref_src=twsrc\%5Etfw\%7Ctwcamp\%5Etweetembed\&ref_url=https\%3A/ /d-12827244291488672835.ampproject.net/2003261442330/frame.html.

4. Ministerio de Salud de la Argentina. Recomendaciones condicionales para el abordaje terapéutico de COVID19 | Argentina.gob.ar; 27 de marzo de 2020.

5. McLaughlin EC. Fearing coronavirus, Arizona man dies after taking a form of chloroquine used in aquariums; 23 de marzo de 2020 . Available from: https://edition.cnn.com/2020/03/23/health/arizona-coronavirus-chloroquine-death/index.html. 